\title{
Comparative Anatomical Observations of the Tongue of the Japanese Long-Fingered Bats, Miniopterus schreibersi fuliginosus
}

\author{
By \\ Shigeru KOBAYASHI and Akitatsu SHIMAMURA \\ Second Department of Oral Anatomy, Kyushu Dental College \\ Kokura-kita, Kitakyushu 803, Japan \\ - Received for Publication, December 2, 1981-
}

Key Words: Japanese long-fingered bat, Tongue, Filiform papillae.

\begin{abstract}
Summary: Observations under a light and a scanning electron microscope were made of the tongue in ten adult Japanese long-fingered bats (Miniopterus schreibersi fuliginosus). The tongue is tapering and has a lingual prominence in the posterior half. On its dorsum are four types of lingual papillae as in other mammals : circum vallote, foliate, fungiform, and filiform papillae. Sulcus terminals, however, are absent. A fan-shaped area of non-papillae is observed extending from the tongue root to the median fungiform papillae and between the circumvallate papillae. Mixture glands open into this area. The filiform papillae notably differ in morphology by their location on the tongue and can be classified into six types: 1) hair-like papillae, 2) filiform papillae, 3) trifid papillae, 4) triangular papillae, 5) saw-like papillae, and 6) conical papillae. The hair-like papillae which cover the anterior half of the tongue are considered to function effectively in catching small insects.
\end{abstract}

The tongue in mammals varies on morphology by the species. Difference in food habit is considered to be one of the reasons. Many-studies on the tongue in mammals have been reported since Tuckerman (1888). Sonntag (1920) in particular reported on the morphology of the tongue apex; morphological classifications of the vallate, foliate fungiform, and filiform papillae; morphological variations by the species; and difference in the number of vallate papillae. Despite a number of reports made to date, relatively few reports have been made on the tongue of bats, which are: the only mammals capable of flying; the second largest group (18 families with 180 genera) among the living mammals ; diversified in food habits, being insectivorous, fruit-eating, or vampire, etc ; and varied in morphology of the tongue, lingual papillae, filiform papillae in particular. Tuckerman $(1888,1890)$ reported on three families and three species, Lautenschlager (1935) on four families and five species, Park and Hall (1951) on three families and eight species, Yamazaki (1953) on one species, and Jaeger (1954) on two families and two species. They clarified the variations in morphology not only of the tongue but also of the lingual papillae, especially of the filiform papillae. 
For this paper, the morphological variations by the location of the lingual papillae, especially of the filiform papillae, are described in detail of the Japanese long-fingered bats (insectivorous), about which few investigations have been reported.

\section{Materials and Methods}

Ten adult Japanese long-fingered bats (about $13 \mathrm{~g}$ in body weight) caught in mid-October in Ohse-do Cave, Kumamoto Prefecture, were guillotined. Some of the tongues were used for macroscopic observations and others were embedded in paraffin after Bouin fixation, sectioned frontally and sagitally, haematoxyline-eosin stained, and observed under a light microscope. Some of the specimens were washed in a physiological salt solution, fixed in neutral formalin, rinsed with running water, dehydrated by a series of alchohol, transferred to isoamyle acetate, and dried in $\mathrm{CO}_{2}$ by the critical point method. Then the specimens were coated with carbon and gold, and examined under a JSM-25 scanning electron microscope (SEM) at $20 \mathrm{Kv}$ of accelerating voltage.

\section{Observations}

The tongue is tapering, about $9 \mathrm{~mm}$ long, and about $5 \mathrm{~mm}$ wide. The tongue is free from the mouth floor in the anterior $4 \mathrm{~mm}$ and has a distinct lingual prominence in the posterior resion. The sulcus terminals and sulcus medianus linguae, seen in other mammals, are absent. On the dorsum are four types of the lingual papillae, as in other mammals (Fig. 1).

The filiform papillae cover the dorsum nearly completely and differ in morphology and in size by their location and their

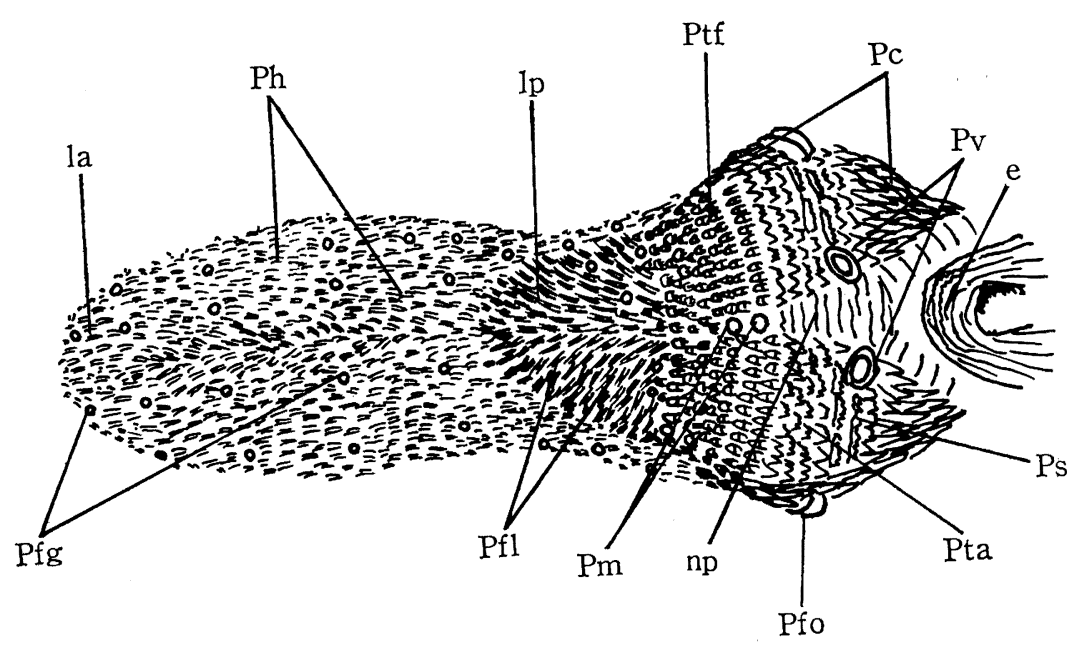

Fig. 1. Schematic drawing of the tongue in Japanese long-fingered bat, Miniopterus schreibersi fuliginosus. e: epiglottis, la: lingual apex, lp: lingual prominence, $\mathrm{np}$ : non-papillae area, Pc: conical papilla, Pfg: fungiform papilla, Pfl: filiform papilla, Pfo: foliate papilla, $\mathrm{Ph}$ : hair-like papilla, $\mathrm{Pm}$ : median fungiform papilla, Ps: saw-like papilla, Pta: triangular papilla, Ptf: trifid papilla, $\mathrm{Pv}$ : circumvallate papilla. 
apical portions are bend toward the posterior direction in general. The anterior half of the tongue is covered evenly with the hair-like papillae described by Sonntag (Figs. $2 \& 3$ ). On the anterior region of the lingual prominence are filiform papillae having fine secondary papillae and their tips are directed toward the lingual apex (Fig. 4). On the lingual prominence posterior to these papillae are trifid papillae (Fig. 5), and several types of triangular papillae: smooth edges, many secondary papillae, or two or three processes. Futhermore, saw-like papillae, fused multiple triangular papillae, are observed (Fig. 6). In the foliate papillae region on the lingual side are the conical papillae (Fig. 7). The fungiform papillae are scattered, in a rather regular arrangement, over the anterior dorsal surface and on the marginal regions of the tongue among the filiform papillae (Figs. 10-13). The fungiform papillae are about $10 \mu \mathrm{m}$ in maximum diameter and have one to three taste buds in the epithelium (Fig. 14). On the lingual prominence, these papillae are localized on the median line and lateral border. Of these, the median fungiform papillae localized on the median line are rather large, about $15 \mu \mathrm{m}$ across, and have three to five taste buds, and mixture glands are located in the muscle layer directly beneath but the gland duct does not open (Fig. 15).

The foliate papillae are located in the form of two folds about $1 \mathrm{~mm}$ long on the lingual posteolateral region anterior to the arcus glasso-palatinus (Fig. 7).

The two circumvallate papillae are found on the lingual root, and irregular deep troughs are found on the papillae surface (Fig. 8).

In the epithelium of the lateral walls of the foliate and circumvallate papillae, many taste buds are located.

The lingual glands are: 1) Ebner's glands (Fig. 16) which open at the lateral walls of the circumvallate and foliate papillae and at the trench bottom; 2) a pair each of mucous glands, on the right and the left side, which open to plica sublingualis; and 3) mixture glands (Figs. 9, 15, 16) which open into the nonpapillae area.

\section{Discussion}

Bats are the only flying mammals and underwent many modifications for flight such as evolving wings. Their food habits are very diversified: insectivorous, fruit-eating, flower-eating feeding on pollen or nectar, vampire, carnivorous feeding on small animals or birds, and even feeding on fish. These differences resulted in various adaptations in the number and the morphology of the teeth. The tongue was no exception and underwent many changes. Park and Hall (1951) made comparative studies of the tongue in a total of three families and eight species, nectareating, fruit-eating, and vampire bats, and classified the filiform papillae into seven types: 1) small flat papillae and bifid papillae (numerous on the anterior region of all bats), 2) large bifid papillae (on the posterior middle area of the tongues of fruit-eating bat, Macrotus and Artibeus), 3) larger bifid horny papillae (near the tongue tip in all bats), 4) hairlike papillae (at the tip of the tongues of the nectar-eating bats), 5) scale-like papillae (at the posterior region in the nectar-eating bat, Macrotus and the insectivorous bat, Eptesicus), 6) disc-like papillae (on the dorsum in the fruiteating bat, Artibeus), and 7) basket-like papillae (on the dorsum of the fruit-eating bat, Carollia). Jaeger (1954) illustrated and classified the filiform papillae of the fruit-eating bats, Eidlon, into four types, namely, conical, trifid, pectinees, and filiform papillae. Thus, the morphology 
of the filiform papillae of the tongue in bats varies greately by their location and by the species.

The Japanese long-fingered bats dats described in this study are as varied in the filiform papillae as others. Their filiform papillae are classfified into six types : 1) hair-like papillae (on the anterior half), 2) filiform papillae (on the anterior region of the lingual prominence), 3) trifid papillae (on the lingual prominence), 4) triangular papillae (on the lingual prominence), 5) saw-like papillae (on the lingual prominence), and 6) conical papillae (in the foilate papillae and the posterior to circumvallate papillae regions). However, the small flat papillae and larger bifid horny papillae, which were reported by Park and Hall as common to three families and eight species, and the scale-like papillae of the insectivorous bat, Eptesicus, were not observed. The scale-like papillae that Park and Hall reported, however, may be similar to the conical papillae described by us. According to Sonntag, the hairlike papillae are long and coarse, or fine, and a cluster may arise from a single point. These papillae are located on each side of the tongue apex of the nectareating bats and the bats soak up nectar from the deep recessed of flowers. Therefore, these papillae are extremely modified and elongated for the purpose, and are generally called bristle-like or long spinous papillae. To term these papillae hair-like, as Park and Hall did, may be mislesding.

Nearly all insectivorous bats are active either at night or at dusk and catch in flight small insects. Moths and beetles are their usual food. The bats bend their wings forward to form a bag and select insects of appropriate sizes for eating. Lautenschlarger (1935) described that in other to agilely catch flying insects during this series of sections and send the food to the pharynx, the lingual prominence and lingual papillae are important and these are especially modified. The Japanese long-fingered bats, according to Funakoshi and Uchida (1975), feed mainly on Lepidoptera of $25 \mathrm{~mm}$ or less in body length and also catch Diptera and Ephemeroptera. The minute hair-like papillae on the anterior half of the tongue are considered most effective and important for instantaneous selection and swallowing in flight of food.

The roles played by the triangular papillae with the flat lingual prominence and by the saw-like papillae, and the significance of the non-papillae area and the mixture glands which open into this area remain to be clarified in the future studies. Determination and detailed examination of the relation of the tongue and the lingual papillae to food habits in other bats is considered to provide a way for clarification of these matters.

\section{Acknowledgements}

The authors also wish to express their sincerce gratitude to Prof. T. Uchida, Mr. T. Mōri, and Dr. K. Funakoshi of Kyushu University for their suggestions and help in regard to literatures. $\mathrm{Mr}$. K. Kimura of Shinshu University kindly offered valuable materials on Japanese long-fingered bat. The technical assiatance of Mrs. K. Okada is greatly appreciated.

\section{References}

1) Funakoshi, K. and Uchida, T.: Studies on the physiological and ecologial adaptation of temperate insectivorous bats 1 . Feeding activites in the Japanese long-fingered bats, Miniopterus scheibersi fuliginosus. Jap. J. Ecol. 25: 217-234, 1975 (in Japanese with English abstract).

2) Jaeger, P.: Les aspects actuels du problème de la Chéiroptèrogamie. Bull. 
Inst. frang. Afr. noire 16:796-821, 1954.

3) Lautenshlager, F.: Über eine besondere Anpassung mechanischer Zungenpapillen an die Nahrungsaufnahme im Fluge bei Fledermäusen. Zool. Anz. Leipzig. 109: 263-266, 1935.

4) Park, H. and Hall, E. R.: The gross anatomy of the tongues and stomachs of eight new world bats. Trans. Kansas Acad. Sci. 54 : 64-72, 1951.

5) Sonntag, C. $!$ F.: The comparative anatomy of the tongue of the mammalia 1. General description of the tongue. Proc. Zool. Soc. Lond. 115-129, 1920.
6) Tuckerman, F.: Observations on the structure of the gustatory organs of the bat, Vespertilio subulatus. J. Morph. 2 (1) : 1-7, 1888.

7) Tuckerman, F.: On the gustatory organs of some of the mammalia. J. Morph. 4 (2) : 151-193, 1890.

8) Yamazaki, E.: Studies on the development of papilla linguale and taste buds of man and mammals 1. Rhinolophus kosidianus. Kaibogakukyoshitsu henpoh, Niigata medical collage. 26:55-83, 1953 (in Japanese). 


\section{Explanation of Figures}

\section{Plate I}

Figs. 2-7. Scanning electron micrograph of the filiform papillae of a bat tongue. The filifom papillae varies by the location. Their apical portions are bend toward the posterior direction in general.

Fig. 2. The hair-like papillae on the anterior half of the tongue. $\times 200$.

Fig. 3. Enlarged photograph of the papillae in Fig. 2. $\times 700$.

Fig. 4. The filiform papillae on the anterior region of lingual prominence. Their tips are directed toward the lingual apex. $\times 100$.

Fig. 5. The tifid papillae on the lingual prominence. $\times 200$.

Fig. 6. The triangular papillae and saw-like papillae on the lingual prominence. $\times 50$.

Fig. 7. The conical papillae on the foliate papilla region. The foliate papilla have two folds. $\times 200$.

Fig. 8. The troughs on the circumvallate papilla surface. $\times 300$.

Fig. 9. Scanning electron micrograph of the non-papillae area. $\times 1,000$. od : opening of duct. 
Plate I
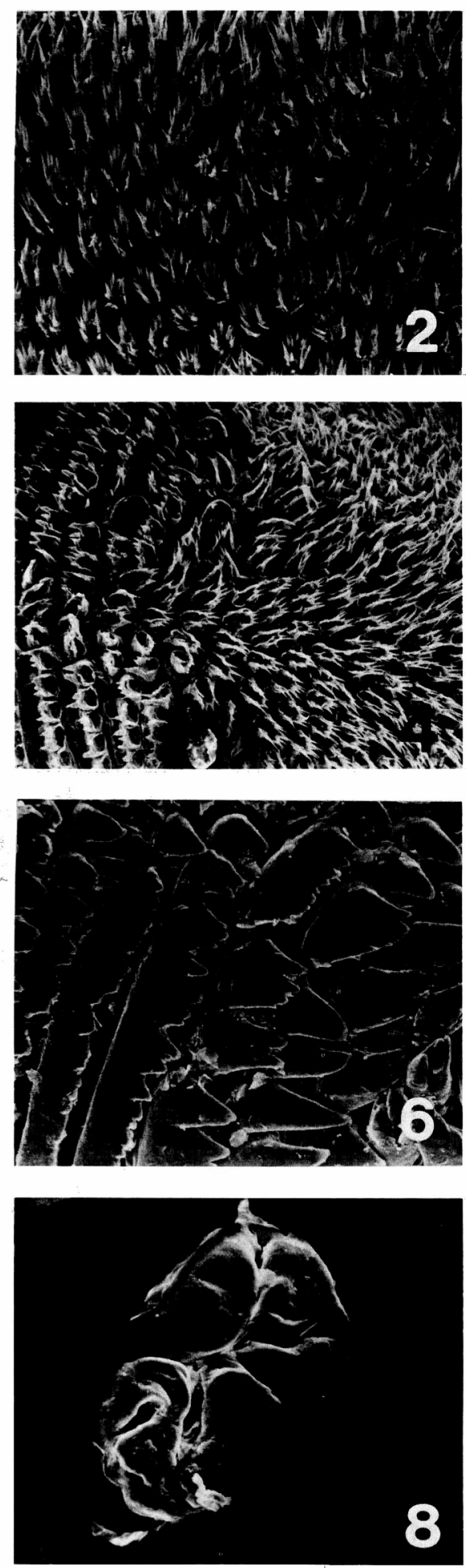

S. Kobayashi and A. Shimamura
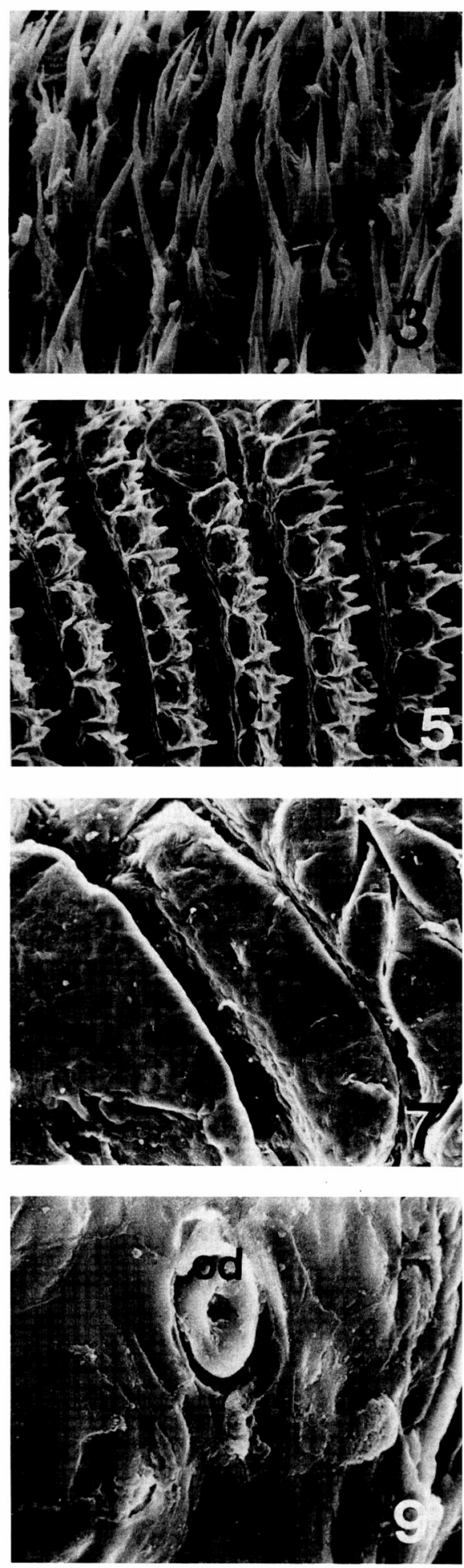


\section{Plate II}

Figs. 10-13. Scanning electron micrograph of the fungiform papillae of a bat tongue.

Fig. 10. A fungiform papilla located among filiform papillae. $\times 450$.

Fig. 11. A slightly protruded fungiform papilla. $\times 300$.

Fig. 12. A slightly recessed fungiform papilla. $\times 700$.

Fig. 13. The median fungiform papillae on the lingual prominence. $\times 300$.

Fig. 14. Frontal section through the fungiform papilla on the dorsum.

Fig. 15. Frontal section through the median fungiform papillae on the lingual prominence. Unlike others, a taste bud is located on each edge. The mucous glands are located in the muscle layer directly beneath.

Fig. 16. Frontal section through the circumvallate papillae.

$\mathrm{Pv}$ : circumvallate papilla, Eg: Ebner's gland, $\mathrm{mg}$ : mucous gland, $\mathrm{sg}$ : serous gland, $\mathrm{np}$ : non-papillae area. 

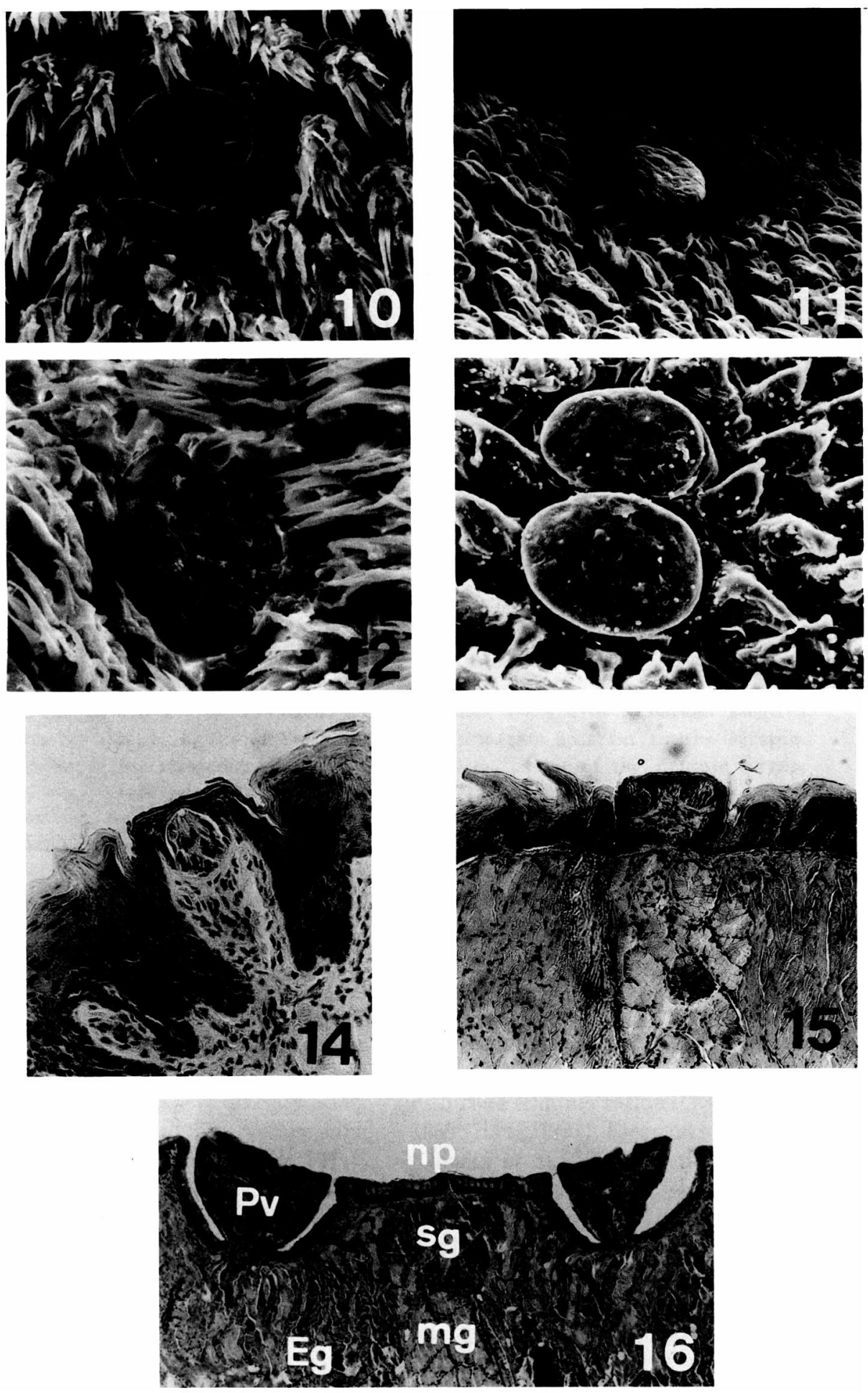

S. Kobayashi and A. Shimamura 